medication use for RA and osteoporosis, and then evaluated the incidence and risk factors for osteoporotic fracture.

Results: The mean age of RA patients was $61.7 \pm 11.9$ years, and 426 patients were female (88.9\%) with 353 postmenopausal women $(82.9 \%)$. The BMD score of L-spine in RA patients was significantly lower than that in healthy control $(-2.21 \pm 1.41$ vs. $0.97 \pm 0.11, p<0.001)$. Osteoporotic fracture was detected in 81 (16.9\%) patients with RA. In RA patients, $226(47.2 \%)$ patients met the FRAX criteria for high risk of osteoporotic fracture, and $240(50.1 \%)$ patients satisfied the WHO criteria. The result of the FRAX criteria was affected by the female sex, menopause, smoking, drinking, higher dose of glucocorticoid ( $\geq 5 \mathrm{mg} /$ day), vitamin $\mathrm{D}$ use, calcium use and proton pump inhibitor (PPI) use $(p<0.05)$. In multiple linear analysis, the FRAX score to 10 -year probability of $\geq 3 \%$ of hip fracture was associated with age $(\beta=0.384, p<0.001)$, body weight $(\beta=-0.110$, $p=0.038)$, erythrocyte sedimentation rate level $(\beta=0.125, p=0.010)$, glucocorticoid dose $(\beta=0.105, p=0.024)$, and PPI use $(\beta=-0.123, p=0.010)$. The independent risk factors for FRAX criteria were age (OR 1.160, $p<0.001$ ), female sex (OR 3.942, $p=0.010$ ), body mass index (BMI) (OR 0.869, $p=0.001$ ), glucocorticoid dose (OR 1.167, $p=0.025$ ) and PPI use (OR 2.552, $p=0.019$ ), and those for WHO criteria were age (OR 1.021, $p=0.040$ ), glucocorticoid dose (OR 1.109, $p=0.046$ ) and smoking (OR 2.924, $p=0.031$ ).

Conclusions: Osteoporotic fractures were found in $16.9 \%$ of RA patients. The proportion of patients with high risk of osteoporotic fracture was $47.2 \%$ in the FRAX model and $50.1 \%$ in the WHO model. Age, female sex, lower BMI, higher dose of glucocorticoid, PPI use and smoking were independent risk factors for osteoporotic fracture in RA patients.

Disclosure of Interest: None declared

DOI: 10.1136/annrheumdis-2017-eular.4580

\section{FRI0534 REPEATED OSTEOPOROSIS SCREENING IN RHEUMATOID ARTHRITIS: ARE WE COMPLYING WITH GUIDELINES?}

A. Gorman ${ }^{1}$, V. Sullivan ${ }^{2}$, S. Khan ${ }^{1}$, A. Mohammed ${ }^{1}$, K. O'Rourke ${ }^{1}$. ${ }^{1}$ Rheumatology; ${ }^{2}$ Midlands Regional Hospital Tullamore, Tullamore, Ireland

Background: Osteoporosis rates are higher in patients with rheumatoid arthritis (RA). Patients with RA diagnosed with osteoporosis have a $30 \%$ increased risk of major fracture [1]. Monitoring response to osteoporosis treatment is recommended however there is no consensus on how frequently this should be performed. The International Society for Clinical Densitometry (ISCD), National Osteoporosis Foundation (NOF) and the American Association of Clinical Endocrinologists (AACE) all recommend repeat Bone Mineral Density (BMD) assessment within two years after initiating osteoporosis treatment to assess response to treatment [2-4]. Furthermore, the NOF and AACE recommend repeat screening every two years after diagnosis $[3,4]$.

Objectives:

- To identify patients with RA and osteoporosis

- To identify if international guidelines are being achieved for reassessment of BMD within two years of treatment commencement in keeping with international guidelines.

Methods: A database of patients with a diagnosis of RA and osteoporosis who attend the Rheumatology department of the Midlands Regional Hospital, Tullamore since January 2013 was reviewed. Outpatient summaries, date of diagnosis, radiology investigations (DEXA scanning), pharmacological treatment and follow up investigations and treatment were documented.

Results: As of August 2016, 770 patients were identified as having RA. 90\% of patients had attended the department since 2013. 117 (16.7\%) patients were identified as having osteoporosis. Of these, $52.14 \%$ of patients were prescribed bisphosphonate therapy, 31.62\% denosumab, 9.4\% calcium/vitamin D alone, $0.85 \%$ other treatment (teriparatide/strontium) and $5.1 \%$ were on no treatment. Only $11.9 \%$ of these patients had a repeat DEXA scan within two years of starting or changing treatment. $11.1 \%$ of patients had repeat DEXA scans booked. The average length of time since a patient's most recent DEXA is 35 months.

Conclusions: Repeat DEXA scanning to assess the response to osteoporosis treatment in people with RA within the timeframe recommended by international guidelines has not been achieved. Patients who fail to respond to osteoporotic treatment are not being identified in a timely manner and therefore are at an increased risk of fractures. The results of this audit will make us more vigilant to identify those patients who are treated for osteoporosis that need repeat DEXA scanning to ensure that treatment is efficacious.

\section{References:}

[1] Kanis JA, Johnell O, Oden A, et al. FRAX and the assessment of fracture probability in men and women from the UK. Osteoporos Int 2008; 19:385.

[2] 2013 ISCD Official Postions - Adult http://www.iscd.org/official-positions/2013iscd-official-positions-adult/ (Accessed on December 02, 2013).

[3] Cosman F1, de Beur SJ, LeBoff MS, et al. Clinician's Guide to Prevention and Treatment of Osteoporosis Osteoporos Int. 2014 Oct;25(10):2359-81.

[4] Watts NB, Bilezikian JP, Camacho PM, Greenspan SL,et al.American Association of Clinical Endocrinologists Medical Guidelines for Clinical Practice for the diagnosis and treatment of postmenopausal osteoporosis. AACE Osteoporosis Task ForceEndocr Pract. 2010 Nov;16 Suppl 3:1-37.

Disclosure of Interest: None declared

DOI: 10.1136/annrheumdis-2017-eular.2459

\section{FRI0535 STRONG INFLUENCE OF VITAMIN D STATUS ON BONE MINERAL DENSITY AND BONE TURNOVER MARKERS DURING WEIGHT RESTORATION IN PATIENTS WITH ANOREXIA NERVOSA}

A. Giollo ${ }^{1}$, L. Idolazzi ${ }^{1}$, C. Caimmi ${ }^{1}$, A. Fassio ${ }^{1}$, F. Bertoldo ${ }^{2}$, R. Dalle Grave ${ }^{3}$, S. Calugi ${ }^{3}$, P.V. Bazzani ${ }^{3}$, O. Viapiana ${ }^{1}$, M. Rossini ${ }^{1}$, D. Gatti ${ }^{1} .{ }^{1}$ Rheumatology Unit, Department of Medicine; ${ }^{2}$ Internal Medicine Unit, Department of Medicine, University of Verona, Verona; ${ }^{3}$ Department of Eating and Weight Disorder, Villa Garda Hospital, Garda, Italy

Background: Anoressia nervosa ( $A N)$ is associated with an increased risk of low bone mineral density (BMD) and fractures as a consequence of an inadequate bone mass peak in adolescence and bone loss in young adulthood. Moreover, recently we have showed that vitamin $D(25-\mathrm{OH}-\mathrm{D})$ deficiency is widespread in untreated patients with $\mathrm{AN}$, and there is a strong positive relationship between vitamin D status and BMD in AN. However, if vitamin D status could affect the efficacy of weight restoration in improving bone health in patients with $A N$ is currently unknown.

Objectives: Our aim was to investigate the potential role of vitamin D status in determining the efficacy on bone mineral density (BMD) of weight restoration in AN.

Methods: Bone mineral density assessed by dual-energy $\mathrm{x}$-ray absorptiometry (DXA), vitamin D, N-propeptide of type I collagen (P1NP), C-terminal telopeptide of type I collagen (CTX), intact parathyroid hormone (PTH) were evaluated before and after a 20 -weeks intensive weight restoration therapy in patients with anorexia nervosa and secondary amenorrhoea for at least 6-months. The subjects were not receiving medications known to affect bone metabolism.

Results: Ninety-one female patients aged 13-45 years old were evaluated, baseline weight $39.4 \pm 5.6 \mathrm{~kg}$ and BMI $15.1 \pm 1.6 \mathrm{~kg} / \mathrm{m}^{2}$. Weight and BMI were significantly increased in all patients after treatment. The mean BMD values were significantly increased only at the spine $(1.0 \pm 3.6 \%, p=0.009)$. A positive trend was demonstrated between post-treatment 25-OH-D and BMD changes at the spine $(p=0.032)$. However, only the patients with post-treatment $25-\mathrm{OH}-\mathrm{D} \geq 30$ $\mathrm{ng} / \mathrm{ml}$ showed significantly higher increases in BMD at the spine $(2.5 \%$ vs $0.5 \%$ respectively for $25-\mathrm{OH}-\mathrm{D} \geq 30 \mathrm{ng} / \mathrm{ml}$ and $25-\mathrm{OH}-\mathrm{D}<30 \mathrm{ng} / \mathrm{ml}, \mathrm{p}<0.03$; Figure 1). Both P1NP and PTH increased, whereas a significant decrease was found in 25-OH-D and CTX $(p<0.05)$. Post-treatment CTX levels were inversely correlated with spine BMD. A positive relationship was found between changes in weight and $\mathrm{P} 1 \mathrm{NP}(\mathrm{R} 2=0.27)$.

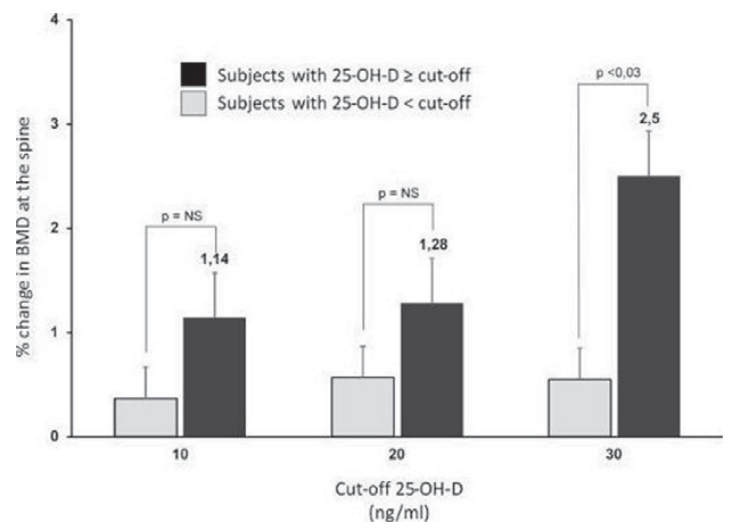

Conclusions: In anorexia nervosa, a hypovitaminosis D status counteracts the efficacy of the weight restoration treatment because of an increase in bone resorption mediated by a secondary hyperparathyroidism. Our study strongly support the use of vitamin D supplements for bone health in anorexia nervosa. Disclosure of Interest: None declared

DOI: 10.1136/annrheumdis-2017-eular.3793

\section{FRI0536 THE METHOD OF CALCULATING THE PROBABLE VALUE OF T-SCORE IN PATIENTS WITH MULTIFOCAL ATHEROCALCIFICATION}

A.N. Kokov, V. Masenko, S. Semenov, O. Barbarash. Federal State Budgetary Scientific Institution Research Institute for Complex Issues of Cardiovascular Diseases, Kemerovo, Russian Federation

Objectives: To determine probable value of T-score for early detection of osteopenic syndrome in patients with multifocal atherosclerosis based on the multislice computed tomography (MSCT) evaluation of vascular calcification.

Methods: 186 male $(60 \pm 6,7$ years) with multifocal atherosclerosis. All the patients underwent the measurement of BMD with X-ray absorptiometry. Moreover, calcium scores (CS) of coronary and brachiocephalic arteries were obtained using Agatston method

Results: T-score values of lumbar vertebrae -1.07 [-1.54;-0.40], T-score of the proximal femur $-2.01[-2.71 ;-1.49]$. Calcification of the coronary arteries: $C S=471.8$ $[118.2 ; 916,8]$ and carotid arteries: $C S=113.9[44.5 ; 300.8]$. Factors that affect the 
probable value of T-score in patients with known rates of calcification of the coronary and carotid arteries were obtained by regression analysis. These factors were equivalent density of coronary calcinoses $(p=0,0046)$, the volume of the carotid calcifications $(p=0,0039)$, the mass of calcifications of the carotid arteries $(p=0,0054)$ and the presence of a stenosis of the carotid arteries $(p=0.0001)$. The predictive model for estimating the probable value of T-score has been is designed using regression coefficients of each of the factors. The value is equal to the Fisher statistic $F=9,52$, $p$-value $<0.000001$, multiple correlation model's coefficient is 0.753 .

Conclusions: The results of this study indicate that rates of calcification of the carotid and coronary arteries, resulting in the planned survey on MSCT patients with multifocal atherosclerosis have a high predictive capacity for assessing the probable value of the T-score and early detection of osteopenic syndrome in these patients.

Disclosure of Interest: None declared

DOI: 10.1136/annrheumdis-2017-eular.5654

\section{FRI0537 PREVENTION STRATEGY OF OSTEOPOROTIC FRACTURES IN PORTUGAL: AN ANALYSES ON A COHORT OF HIP FRACTURED PATIENTS}

A. Daniel ${ }^{1}$, M.L. Marques ${ }^{1}$, L. Brites ${ }^{1}$, C. Torres $^{2}$, A. Marques ${ }^{1}$, J.A. Pereira da Silva ${ }^{1} \cdot{ }^{1}$ Rheumatology Unit, Centro Hospitalar e Universitário de Coimbra; ${ }^{2}$ Rheumatology Unit, Faculdade de Medicina da Universidade de Coimbra, Coimbra, Portugal

Background: Despite the fact that Portugal has one of the lowest rates of hip fractures in Western Europe, more than 10.000 patients are admitted every year to the Portuguese National Health Service due to hip fragility fractures. The burden of the problem will tend to increase in coming years, unless effective preventive measures are put in place. ${ }^{1}$

Objectives: The aim of our work was to evaluate the percentage of patients under osteoporotic treatment (OT) before and after a hip fracture (HF) and compare these results with the percentage of patients who should be under treatment, according to FRAX model and Portuguese cost-effectiveness guidelines (PG) for OT. ${ }^{1}$

Methods: Patients diagnosed with a HF, between May 1st and October 31st 2013, from a single tertiary hospital, were included in this transversal study. Patients or their primary caregiver were contacted by phone to gather data regarding demographic and clinical features, including risk factors for Osteoporosis (OP) defined by FRAX ${ }^{\circledR}$. Clinical data was obtained from medical files.

FRAX ${ }^{\circledR}$ without mineral bone density was used to calculate the 10 year fracture risk. For each patient the $F R A X^{\circledR}$ was scored according to data available the day before the present $\mathrm{HF}$ (ie the current fracture was not considered as a previous fracture for the purpose of risk prediction). Thresholds for therapeutic intervention were defined according to PG: a 10-year probability of a major osteoporotic fracture (OF) $\geq 11 \%$ and/or a 10 year probability of $\mathrm{HF} \geq 3 \%{ }^{1}$.

Results: The mean age of the population $(n=130)$ was $81.6 \pm 8.6$ years, and $69.2 \%$ were female. Before the current HF, only $23(17.7 \%)$ of the patients had been prescribed some form of medication for OP: bisphosphonates $(n=2)$, strontium ranelate $(n=3)$ and calcium + vitamin D supplementation $(n=13)$; the other patients or caregivers didn't specify the ongoing medication.

About 65 patients had a previous fracture, of which 8 patients had $\geq 1$ fragility fracture of the hip; 6 had $\geq 1$ symptomatic vertebral fragility fracture and 16 had $\geq 2$ fragility fractures, independently of the site of the fracture. According to $P G$, all these $30(26 \%)$ patients should be under OT without the need for FRAX ${ }^{\circledR}$ risk calculation.

The mean 10 -year major OF probability was $21.2 \pm 14 \%$ and the mean 10 -year HF probability was $13.7 \pm 12.9 \%$. According to FRAX ${ }^{\circledR}, 104(80 \%)$ of the patients had indication to start OT based on the 10-year risk of major OF and $117(90 \%)$ based on the 10-year risk of HF.

After hospitalization, although all the patients had formal indication for treatment, only $11(8.5 \%)$ patients had received a prescription for OT up to one year after the fracture event.

Conclusions: Similar to other countries, the percentage of patients under OT (before and after HF) in Portugal is extremely low. Risk estimation by FRAX ${ }^{\circledR}$ and application of current PG would allow clinicians to identify these patients and introduce appropriate preventive measures. Continued efforts are needed to promote timely prevention, most especially after the first fragility fracture.

\section{References:}

[1] Marques A, Rodrigues AM, Romeu JC et al. Multidisciplinary Portuguese recommendations on DXA request and indication to treat in the prevention of fragility fractures. Acta Reumatol Port 2016;41:305-321.

Disclosure of Interest: None declared

DOI: 10.1136/annrheumdis-2017-eular.3277

\section{FRI0538 EVALUATION OF FACTORS THAT INCREASE FRACTURE RISK IN BREAST CANCER}

A. Anand ${ }^{1}$, M. Ghafouri ${ }^{2}$, M. Bukhari ${ }^{1} .{ }^{1}$ University Hospitals of Morcambe Bay NHS Foundation Trust; ${ }^{2}$ Lancaster University, Lancaster, United Kingdom

Background: Women with breast cancer are at an increased risk of fractures.
This is present in patients with both active and treated disease. In addition to established risk factors of fractures, patients with breast cancer are exposed to additional factors that further compromise bone strength. These factors primarily include: the malignancy interfering with bone metabolism and breast cancer treatments inducing bone loss.

Objectives: To evaluate fracture risk in active and treated breast cancer patients, and to understand the role bone mineral density (BMD) plays in predicting fracture risk.

Methods: The study population included breast cancer patients with active and treated disease referred to dual-energy X-ray absorptiometry (DEXA) scanning at the Royal Lancaster Infirmary between 2004-2015. Patients on aromatase inhibitors were excluded because of its' negative effect on oestrogen.

From this population, we collected BMD measurements of the femur and lumbar vertebra. Alongside information on physical characteristics such as age, height, weight, body mass index (BMI), average tissue thickness, lean and fat mass were measured.

To evaluate other precipitating factors known to increase fracture risk we included: smoking status, steroids use, alcohol, family history of fractures, diagnosis of rheumatoid arthritis and secondary osteoperosis.

Data analysis was done on R 3.3.2 software. Odds ratios were calculated using logistic regression and age adjusted models were compared using the likelihood ratio test. Categorical data was analysed using Chi squared and Fischer's exact test, while continuous data was analyzed using t-test.

Results: The study population was a total of 306 patients with a mean age of 63.6 years. 146 of the study group had active disease, while 160 patient were breast cancer survivors. Of the total population $87(28 \%)$ had sustained at least one fracture.

Active breast cancer insignificantly increased fracture risk in comparison to the cancer survivor population $(O R=1.330,95 \% C l=0.801-2.218, p=0.271$ ).

Physical characteristics that significantly increased fracture risk included increased age and decreased average fat percentage (Table 1). BMD reduction in the femoral neck and all vertebrae significantly increased odds of having a fracture (Table 2). External factors such as smoking status, alcohol consumption, family history and steroid use had no significant effect.

Table 1. Physical Characteristics and Fracture Risk

\begin{tabular}{lccc}
\hline & Odds Ratio & 95\% Confidence Interval & $p$-value \\
\hline Age & 1.407 & $1.106-1.803$ & 0.043 \\
BMI & 0.832 & $0.639-1.074$ & 0.159 \\
Average Tissue Thickness & 0.929 & $0.847-1.016$ & 0.108 \\
Average Fat Percentage & 0.069 & $0.005-0.883$ & 0.040 \\
Fat Mass & 0.997 & $0.994-0.999$ & 0.032 \\
Lean Mass & 1.003 & $1.000-1.006$ & 0.032 \\
\hline
\end{tabular}

Table 2. BMD Results from DEXA Scan

\begin{tabular}{lccc}
\hline & Odds Ratio & 95\% Confidence Interval & $p$-value \\
\hline Left Neck of Femur & 0.035 & $0.035-0.309$ & 0.002 \\
Right Neck of Femur & 0.063 & $0.006-0.561$ & 0.013 \\
Lumber Vertebra Total (L1-4) & 0.063 & $0.013-0.285$ & 0.0002 \\
\hline
\end{tabular}

Conclusions: In conclusion, this study emphasizes DEXA measurements are the best predictive tool for fractures in breast cancer patients. Thus further supporting the need for increased BMD surveillance for those diagnosed with breast cancer who are not on aromatase inhibitors.

References:

[1] Body J: Increased fracture rate in women with breast cancer: a review of the hidden risk. Body BMC Cancer 2011, 11:304.

[2] R Core Team (2016). R: A language and environment for statistical computing. R Foundation for Statistical Computing, Vienna, Austria.

Disclosure of Interest: None declared

DOI: 10.1136/annrheumdis-2017-eular.3829

\section{FRI0539 IMPACT OF THE IMPLEMENTATION OF A FRACTURE LIAISON SERVICE IN PHARMACEUTICAL EXPENSES FOR OSTEOPOROSIS}

A. Naranjo $^{1}$, S. Ojeda ${ }^{1}$, S. Rodriguez ${ }^{2}$, I. Bernardos ${ }^{1}$, A. Molina ${ }^{1}$, F. de la Nuez $^{3}$, M. Negrin ${ }^{4} .{ }^{1}$ Rheumatology; ${ }^{2}$ Geriatrics, Hospital Univ. Gran Canaria Dr. Negrin; ${ }^{3}$ Rational Drug Use Service, Servicio Canario de la Salud; ${ }^{4}$ Met. cuantitativos en Economia, Universidad de Las Palmas, Las Palmas de Gran Canaria, Spain

Background: In 2012 a Fracture Liaison Service (FLS) was implemented in Hospital Dr Negrin

Objectives: To analyze the economic impact of the FLS on pharmaceutical expenditure for osteoporosis.

Methods: Expenditure on osteoporosis medication (government inpunt) was collected from January 1th, 2011 to October 1th, 2016. The data distinguish group I (calcium and vitamin D), group II (Bisphosphonates, denosumab, SERM, strontium and teriparatide) and total expenditure (sum of groups I and II). Intravenous bisphosphonates were not included.

Gran Canaria island is organized in two health areas; the North and the South areas. The population aged $>65$ years in the North and South areas in 2016 were 